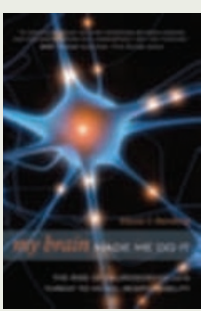

To what extent are we in control of our actions? Not as much as we think, says neuroscientist Eliezer Sternberg in My Brain Made Me Do

It (Prometheus Books, 2010). Exploring thorny issues of moral responsibility in the light of recent developments in neuroscience, Sternberg asks how the brain operates when we exercise our will, whether future criminals might be spotted from their brain chemistry and how consciousness might have evolved.

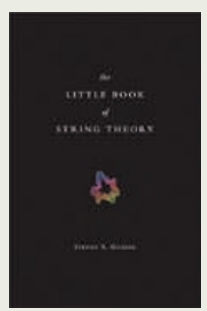

The Little Book of String Theory (Princeton Univ. Press, 2010) by theoretical physicist Steven Gubser puts into words the abstract maths of some of the most challenging areas of physics, from energy and quantum mechanics to branes, supersymmetry and multiple dimensions. Describing the field as "promising" rather than esoteric, Gubser emphasizes string theory's links to other areas of physics and anticipates forthcoming results from the Large Hadron Collider at CERN, Europe's particle-physics laboratory near Geneva, Switzerland, that will test the theory.

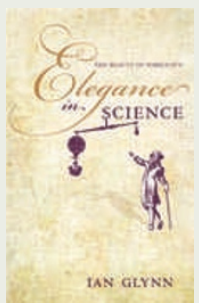

In Elegance in Science (Oxford Univ. Press, 2010), physiologist lan Glynn examines why we find a good experiment or theory so

satisfying. Detailing a range of beautiful and imaginative discoveries across the history of science, from Johannes Kepler's determination of the laws of planetary orbits to elucidation of the structure of DNA, Glynn concludes that economy and creativity are the qualities that bring us most aesthetic pleasure.

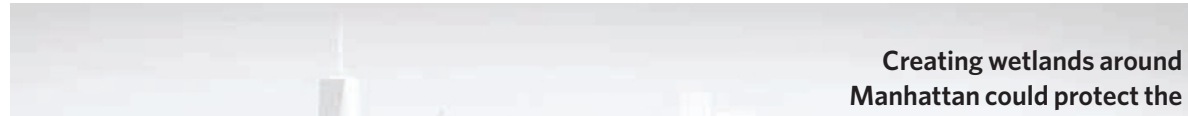
city from rising waters.

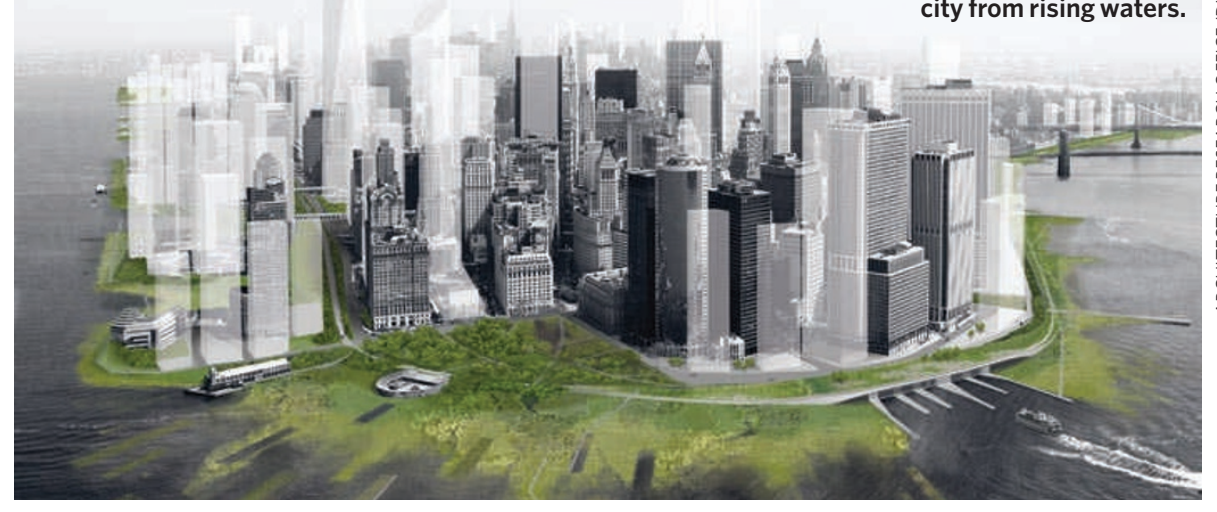

\title{
Artificial reefs to buffer New York
}

\section{Rising Currents: Projects for New York's Waterfront \\ Museum of Modern Art, New York Until 11 October 2010}

Within the next 40 years, projected sea-level rises of up to a third of a metre threaten coastal cities, including New York. By 2100, rising sea levels could inundate $21 \%$ of Lower Manhattan at high tide and warmer ocean temperatures could bring more frequent hurricanes, accompanied by storm surges 7 metres high.

On show until October at New York's Museum of Modern Art (MoMA) are five proposals for shielding low-lying areas of the city from encroaching waters. Each addresses a different zone, from Lower Manhattan to the New Jersey coast, using principles that have global applications. Rather than relying on defensive barriers, such as levees and sea walls, the local design teams participating in Rising Currents suggest using wetlands, artificial islands and living reefs to absorb water and attenuate waves.

In the project Oyster-Tecture, Kate Orff and her team from the urban design studio SCAPE/ Landscape Architecture plan to seed oysters in the waters of the Bay Ridge Flats off Brooklyn to recreate a long-lost natural oyster reef. The SCAPE project also encompasses the Gowanus Canal, a former industrial waterway polluted by pesticides and heavy metals. Oyster beds act as a natural filtration system, and could clean millions of litres of harbour water each day - a single oyster can filter 3 litres of water an hour.

“The project doesn't require a billion-dollar investment, just biology in the form of the oyster," says Orff. A model of Oyster-Tecture, a rope and timber "mosaic landscape for marine life and people" populated by wooden birds, turtles, fish and human figures, has been hand-knitted by the Brooklyn-based Bergen Street Knitters.

A dredged-up oyster shell sits beside Matthew Baird Architects' model of 'Working Waterline', a scheme for the low-lying lands of Bayonne, New Jersey, and the Kill van Kull, the tidal strait that separates them from Staten Island. The company proposes creating an artificial reef and breakwater by sinking thousands of 75-centimetre-high recycled-glass 'jacks' (shaped as in the game) into the sea bed. Accumulated sediment, explains ecologist and artist Nim Lee, would host algae and create habitats for marsh grasses and marine life.

Local warehouses and piers could be converted to recycle the necessary materials: New Yorkers discard nearly 3,000 tonnes of glass each week, of which only around half is recycled. Bayonne's 'tank farm' of industrial containers - used in an infamous 1960s 'salad-oil swindle', in which a commodities trader conned banks out of US $\$ 150$ million by pretending the mostly water-filled tanks were full of soybean oil - could be turned into a sewage-fertilized algae farm producing algal oils for biodiesel as a project by-product.

Water overflow is a persistent problem in New York: thanks to outmoded sewers, more than 100 billion litres of raw sewage and polluted storm water are discharged into the harbour each year. In their project 'A New Urban Ground', Architecture Research Office (ARO) and designers dlandstudio suggest filling the streets of Lower Manhattan with 'greenways' freshwater wetlands and saltwater marshes that act as sponges. "We didn't envision it to be an apocalyptic scene of nature overtaking the city," says Adam Yarinsky of ARO. "It's very much about the city perpetuating, not diminishing."

Population growth is another factor to take into account: New York City is projected to grow by 800,000 people by 2030 . Extending the 
city into the water is the goal of 'New Aqueous City', which covers Sunset Park, Bay Ridge and Staten Island. Designers nArchitects' solution is to build an archipelago of concrete islands connected by inflatable storm barriers that accumulate silt and provide resilience against storm surges. In 'Water Proving Ground', LTL Architects propose a series of landscaped finger-shaped piers for the zone that includes Liberty State Park and the Statue of Liberty.

Curator Barry Bergdoll of MoMA hopes that the projects will be realized: "I don't want them to become like [French architect EtienneLouis] Boullée's late-eighteenth-century paintings in which a seemingly impossible future is projected. We want them to percolate into real projects or into public policy."

Josie Glausiusz is a journalist based in New York.

\section{Q\&A: John Sims on mathematical art}

While pursuing his doctorate in dynamical systems, John Sims was drawn to explore the connections between mathematics and art. Now curating a year-long series of maths-art shows at the Bowery Poetry Club in New York City, the conceptual artist explains the cultural significance of maths.

\section{What is mathematical art?}

It is art that embraces the spirit, language and process of mathematics. Both maths and art are concerned with truth, but they differ in their ways of searching for it. Maths uses analysis and proof; art uses the senses and emotions. But maths can harness the spirit of creativity and art can be analytical. Together they form a great alliance for understanding the world around us.

\section{How did you come to straddle both worlds?}

I grew up in Detroit, Michigan, and became interested in maths through a high-school science-fair project on Pythagorean triples. It was in graduate school that I started to connect maths and art. I taught a calculus course where I allowed the students to make a 'cheat sheet' of notes and formulae to take into the exam. One was visually stimulating, so I bought it. Later, I met mathematician John Horton Conway and sculptor Brent Collins who got me excited about visual maths and art. Soon after, I went to Ringling College of Art and Design in Sarasota, Florida, to develop a maths curriculum for art students.

\section{Why run a series of maths-art shows this year in New York City?}

The aim of the Rhythm of Structure series is to create an opportunity for call-and-response across maths, art and poetry - where mind meets hand meets heart. The hope is to balance the emptiness of pop culture with work that encourages deeper thinking. Nine exhibitions deal with the geometric, conceptual and social aspects of mathematical art. The geometry series included works by mathematicians Mike Field, Davide Cervone and Carlo Séquin. Another show examined how statistics can be used to distort the truth. The current exhibition includes a large geometric drawing by the late artist Sol LeWitt and a response to it by artist Adrian Piper, in the form of a 2-metre-square 'wall deletion'

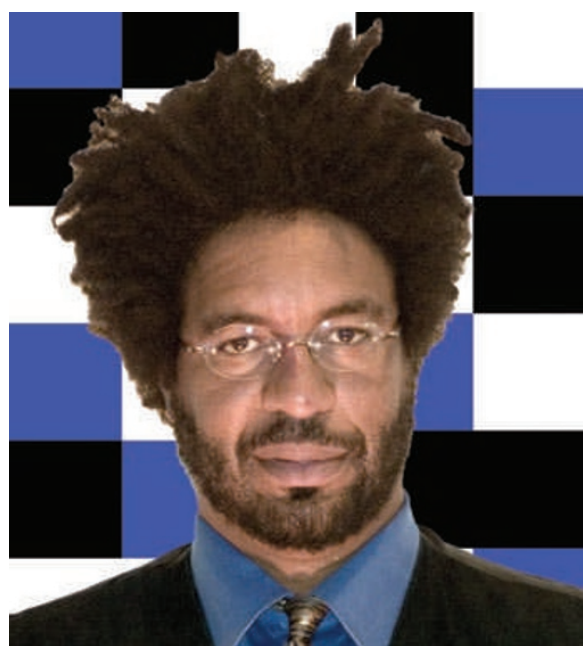

that exposes beam and brick. Mark Strand, the former US Poet Laureate, responded to the pairing in verse.

\section{Can art be useful in teaching maths?}

Sometimes. However, I think maths education is failing marginalized groups such as artists. It would be better if maths was presented less as a slave to science and more as a partner to art. Our next set of shows engages students and teachers. A class at the Brooklyn Academy of Science and the Environment is preparing a giant tessellation, inspired by M. C. Escher, that will cover a wall. Later, we will open that wall to mathematicians and maths educators, who will use the language of maths to create graffiti that will let them see their own formal symbols as objects of art, challenging the distinction between the two fields.

\section{Do views of maths differ across cultures?}

Ethnomathematics is the study of how maths is embedded in culture. One can ask how the prevailing ideas of a culture have shaped its maths. Or one can search for maths in cultural artefacts, such as the patterns in Native American basket weaving or the fractals that are said to be found in
Jackson Pollock's paintings. Paulus Gerdes, an educator and mathematician from Mozambique, has written extensively on how native mathematical thinking can inspire contemporary work. I have translated a knot diagram that Gerdes designed - inspired by African and Celtic sources - into a rope sculpture. For the last show of the series, we will create a wall of mathematical quilts from all over the world.

\section{What will you work on next?}

I am finishing a project featuring 13 quilts based on visualizations of pi and Pythagorean triples, in collaboration with Amish quilters from Sarasota. After that, I am developing an online virtual Museum of Mathematical Art.

\section{Who has influenced you?}

I am inspired by Pythagoras, who saw maths sitting at the centre of art, life and nature. I admire the work of the sixteenth-century painter Albrecht Dürer, particularly his use of magic squares [number grids in which every row, every column and the diagonals sum to the same constant]. I like the way that M. C. Escher was able to draw on the tradition of Islamic geometric art in a representational context, and I like his lithograph of an impossible waterfall inspired by the work of British mathematician Roger Penrose. In the conceptual realm, I like the surrealist artist Marcel Duchamp for his subversive audacity. However, my greatest influence is the unfolding system of structures, patterns and cycles of nature itself.

Interview by Jascha Hoffman, a writer based in San Francisco, California.

e-mail: jascha@jaschahoffman.com

Rhythm of Structure: Mathematics, Art, and Poetic Reflection Bowery Poetry Club, New York City Until 30 August 2010. See go.nature.com/ZCUbdS for details. 